\title{
Quantitative measures of sedimentation in an estuarine system and its relationship with intertidal soft-sediment infauna
}

\author{
Marti J. Anderson ${ }^{1}$, Richard B. Ford ${ }^{1,2, *}$, David A. Feary ${ }^{2}$, Claire Honeywill ${ }^{2}$ \\ ${ }^{1}$ Department of Statistics and ${ }^{2}$ Leigh Marine Laboratory, University of Auckland, Private Bag 92019, Auckland, New Zealand
}

\begin{abstract}
Increased sedimentation from changes in land use in coastal areas is a potentially important impact of human urbanisation. The potential impact of sedimentation on benthic infauna was quantitatively investigated in the Okura estuary, which is at the northern fringes of urban development in Auckland, New Zealand. A structured mensurative sampling programme, measuring benthic infauna and various environmental variables, is described. Of the variance in macrofaunal assemblages from 15 sites throughout the Okura estuary on 6 sampling occasions, $70 \%$ was explained by environmental variables. Proportions of ambient sediment grain-sizes, depositional categories from previous models, the amount and characteristics of trapped sediments, organic content, changes in bed height and distance from the mouth of the estuary were all useful in explaining variation in macrofaunal assemblages. Levels of sedimentation recorded in this study were sub-catastrophic $(<3 \mathrm{~cm}$ of deposition $\mathrm{d}^{-1}$ ), corresponding to natural fluctuations in sedimentation. Bivalves generally had a negative relationship with sedimentation, while certain burrowing crabs and polychaetes were more abundant in high-deposition environments. The total amount and the grain-size characteristics of trapped sediments explained a significant proportion of the variation in soft-sediment assemblages, over and above the variation explained by ambient sediment variables. Thus, sedimentation appears to be an important structuring force in these intertidal estuarine macrobenthic assemblages.
\end{abstract}

KEY WORDS: New Zealand - Intertidal - Soft sediment - Sedimentation · Estuarine Impact · Macrofauna Resale or republication not permitted without written consent of the publisher

\section{INTRODUCTION}

Estuarine mudflats are one of the most productive natural ecosystems on earth, with a gross primary productivity of up to $10 \mathrm{kcal} \mathrm{m}^{-2} \mathrm{yr}^{-1}$ (Kennish 1995). These areas are under increasing pressure from urbanisation, with $50 \%$ of the world's population now living by the coast (GESAMP 1990). Many naturally occurring factors have been recognised as important in influencing marine benthic soft-sediment communities, including grain-size and type of sediment (Gray 1974), predation (Oliver \& Slattery 1985), parasitism (Thomas et al. 1998), disturbance (Probert 1984), supply of colonisers (Armonies \& Hellwig-Armonies 1992), competition (Byers 2000) and food supply (Hentschel \&
Jumars 1994). Anthropogenic activities can also affect these communities, through pollution (Pearson \& Rosenberg 1978), trawling (Thrush et al. 1998), dredging (Quigley \& Hall 1999) and sedimentation (Norkko et al. 2002).

Human activities have caused increased levels of sediment deposition and water turbidity in coastal areas throughout the world by increasing soil erosion and runoff from land clearance, dredging and land reclamation (Ellis 1988, Vogt \& Schramm 1991, Chou 1996). Increased sedimentation in freshwater rivers and streams is well documented as having deleterious effects on fauna (see review by Wood \& Armitage 1997). Increased sedimentation caused by human activities has also been shown to impact estuarine and 
coastal diversity over both large (100s of $\mathrm{km})$ and small (cm) spatial scales (Peterson 1985, Smith \& Kukert 1996, Airoldi \& Cinelli 1997, Edgar \& Barrett 2000, Norkko et al. 2002). In soft-sediment systems, Edgar \& Barrett (2000) found a negative correlation between levels of human settlement and the abundance and productivity of benthic macrofauna over large spatial scales $(100 \mathrm{~s}$ of $\mathrm{km})$. At intermediate spatial scales $(\mathrm{km})$, assemblages with low diversity and productivity have been described from areas with high gross sedimentation rates (Smith \& Kukert 1996). On smaller spatial scales (m), deposition of terrigenous sediments in excess of $3 \mathrm{~cm}$ deep on sandflats (mimicking a landslide) has been shown to decrease the number of macrofaunal individuals by $90 \%$ after $10 \mathrm{~d}$ (Norkko et al. 2002). Field observations and laboratory trials have also shown that catastrophic depositions of sediment (10 cm deep) negatively impact suspension-feeding bivalves (Peterson 1985). The potential effects on macrofaunal communities of the deposition of smaller amounts of sediment in estuaries (as may occur naturally between periods of heavy rainfall) are, however, poorly understood.

To understand the importance of sedimentation, we need to compare the size and direction of its effects with those of other potentially important environmental factors. If significant variation in macrofaunal communities can be explained by environmental variables, this can provide effective models of the fauna for monitoring programmes and predictions (Peters 1991). Previous spatial models of organisms in soft-sediment habitats have found that between 10 and $70 \%$ of the variation in counts of 2 bivalve species over a sampling grid at 2 times could be explained by physical and biological factors (Legendre et al. 1997). Ysebaert et al. (2002) used logistic regression models with environmental predictor variables to explain 79 to $93 \%$ of the variance in the presence/absence of 10 species from an estuary. In addition, $>70 \%$ of the variability in softsediment assemblages in the Schelde estuary of the Netherlands was explained by environmental predictor variables in a canonical correspondence analysis (Ysebaert \& Herman 2002). Local environmental variables (mud content, chlorophyll $a$, bed level height and salinity) were the most useful factors in explaining variation in that community. More modelling of whole communities over time and space is needed for a better understanding of what factors are controlling the structure of soft-sediment assemblages (Constable 1999). Multivariate modelling has been used successfully to assess the importance of sedimentation variables for hard-substrate communities (Saiz-Salinas \& Urkiaga-Alberdi 1999). A combination of multivariate and univariate analyses could prove useful for measuring the response of whole communities to sedimenta- tion and for determining which taxa are most affected by sedimentation.

The Okura estuary is located at the northern edge of the Auckland metropolitan area, and its terrestrial catchment is under increasing pressure from urbanisation. This increasing pressure of development has raised concerns that potential associated increases in sedimentation will negatively impact the ecology of the estuary. Such concerns are particularly relevant, given the status of the Okura estuary as a marine reserve. In this study, we examined the relationship between macrofaunal soft-sediment assemblages and various environmental variables (including measures of sediment deposition) within the Okura estuary over a 9 mo period from August 2001 to April 2002. This spans the time of year when any future land-clearance or construction is likely to occur (i.e. austral summer). It was not the purpose of this study to exhaustively characterise the sedimentation or physical characteristics at each site. Rather, physical measures were chosen that could be recorded over relevant temporal and spatial scales and that were likely to be related to changes in macrofaunal assemblage structure. It is only against a model of the responses of organisms to the natural dynamics of ambient sediments, bed movement (erosion and accretion) and sediment inputs in the estuarine system that the effects of any future increase in sedimentation can be assessed.

\section{MATERIALS AND METHODS}

Study sites and sampling methods. The Okura estuary $\left(174^{\circ} 43^{\prime} 00^{\prime \prime} \mathrm{E}, 36^{\circ} 40^{\prime} 30^{\prime \prime} \mathrm{S}\right)$ is approximately $600 \mathrm{~m}$ wide, and stretches $3.5 \mathrm{~km}$ inland (Fig. 1). It has a tidal range of approximately $3 \mathrm{~m}$ and is subject to water temperatures of 14 to $24^{\circ} \mathrm{C}$ and salinities of 25 to 33 PSU. The Okura estuary is aligned with the dominant wind direction in the region, which is from the southwest (Turner et al. 1995). The terrestrial catchment is dominated by pastureland, with approximately $10 \%$ of the catchment being forested.

The depositional probabilities of different areas within the Okura estuary have been modeled (Green \& Oldman 1999). For this modelling the estuary was divided into 17 different sub-environments based on bed sediments, exposure and distance from the head of the estuary. Computer models of currents, sediment transport and wind-driven waves within the estuary were generated and calibrated using field measurements. A $1000 \mathrm{~kg}$ load of sediment was included in the models of the estuary under a number of differing physical scenarios, including variation in the timing of release, state of the tide and tidal range. The likelihood of the deposition of a $2 \mathrm{~cm}$ thick layer of sediment 
(deemed ecologically critical: Norkko et al. 1999) over an area of $100 \mathrm{~m}^{2}$ in each sub-environment was then calculated, given its particular physical characteristics. A ranking of 'high', 'medium' or 'low' was then mapped across different areas within the estuary to indicate the probability that a $2 \mathrm{~cm}$ thick layer of sediment would be deposited under these physical models (Cooper et al. 1999, Green \& Oldman 1999).

For the present study, 5 sites were selected from each of the 3 deposition regimes: 'high', 'medium' and 'low', as modelled by Green \& Oldman (1999) and summarised in maps of the estuary provided by Cooper et al. (1999). Thus, a total of 15 sites was sampled within the estuary. Each site was located in the mid-intertidal zone and was $50 \mathrm{~m}$ long (parallel to the channel) and $25 \mathrm{~m}$ wide (in an upshore direction), and was chosen to be as homogeneous as possible in terms of tidal height and grain size. The sites covered a wide range of habitats in the estuary, in terms of grain sizes of sediments and distance from the mouth. It is also important to note that not all 'high'-deposition sites were in the upper reaches of the estuary: different depositional environments from the Green \& Oldman (1999) model are spatially interspersed throughout the estuary. All 15 sites were sampled on each of 6 occasions over a period of 9 mo (August 2001 to April 2002) in September, October, November and December of 2001 and in February and March of 2002. The sampling was stratified seasonally, but temporal variability in these communities was extremely small compared to spatial effects and will be discussed elsewhere.

On each sampling occasion, 6 randomly positioned cores were obtained from each site to sample macrofauna. Within each $50 \mathrm{~m}$ long $\times 25 \mathrm{~m}$ wide site, the position of each core was obtained by choosing a random number of metres between 0 and 49 (for the alongshore coordinate) and between 0 and 24 (for the coordinate perpendicular to the shore). Cores were cylindrical in shape, $13 \mathrm{~cm}$ in diameter and $15 \mathrm{~cm}$ deep. Each core was sieved in the field using $0.5 \mathrm{~mm}$ mesh. Material retained on the sieve was brought back to the laboratory for sorting and taxonomic identification. Material retained was preserved in $10 \%$ formalin with $0.01 \%$ Rose Bengal and later transferred to $70 \%$ ethanol. All organisms were identified to the lowest possible level of taxonomic resolution given time constraints and available expertise. For example, most polychaetes were identified to family or genus, and molluscs to species, while nemerteans were counted together as a phylum.

Ambient grain size and sediment organics were each sampled using a $3.8 \mathrm{~cm}$ diameter corer to a depth of $15 \mathrm{~cm}$ at a position adjacent to each faunal core, so that 6 cores were taken for these parameters at the same time as the 6 macrofaunal cores were extracted. Surface microalgae were measured from sediment obtained using the same corer, but slicing off and retaining only the top 2 to $3 \mathrm{~mm}$.

Samples of ambient grain sizes of sediments at each site were analysed from 1 sampling occasion only (February 2002). A subsample was sieved through $2 \mathrm{~mm}$ mesh, deflocculated $(0.2 \%$ Calgon for $24 \mathrm{~h})$ and then analysed using a Malvern Mastersizer-S laser particle-size analyser. Organic content and chlorophyll a were measured at each sampling time. Sediment organic content was calculated from loss of weight on ignition of dried sediment samples at $550^{\circ} \mathrm{C}$ for $6 \mathrm{~h}$. Microalgal biomass was estimated from the amount of chlorophyll a extracted. Chlorophyll a was extracted from sediments using dimethylformamide, measured on a spectrophotometer, and correlated to biomass using standard equations (Porra et al. 1989).

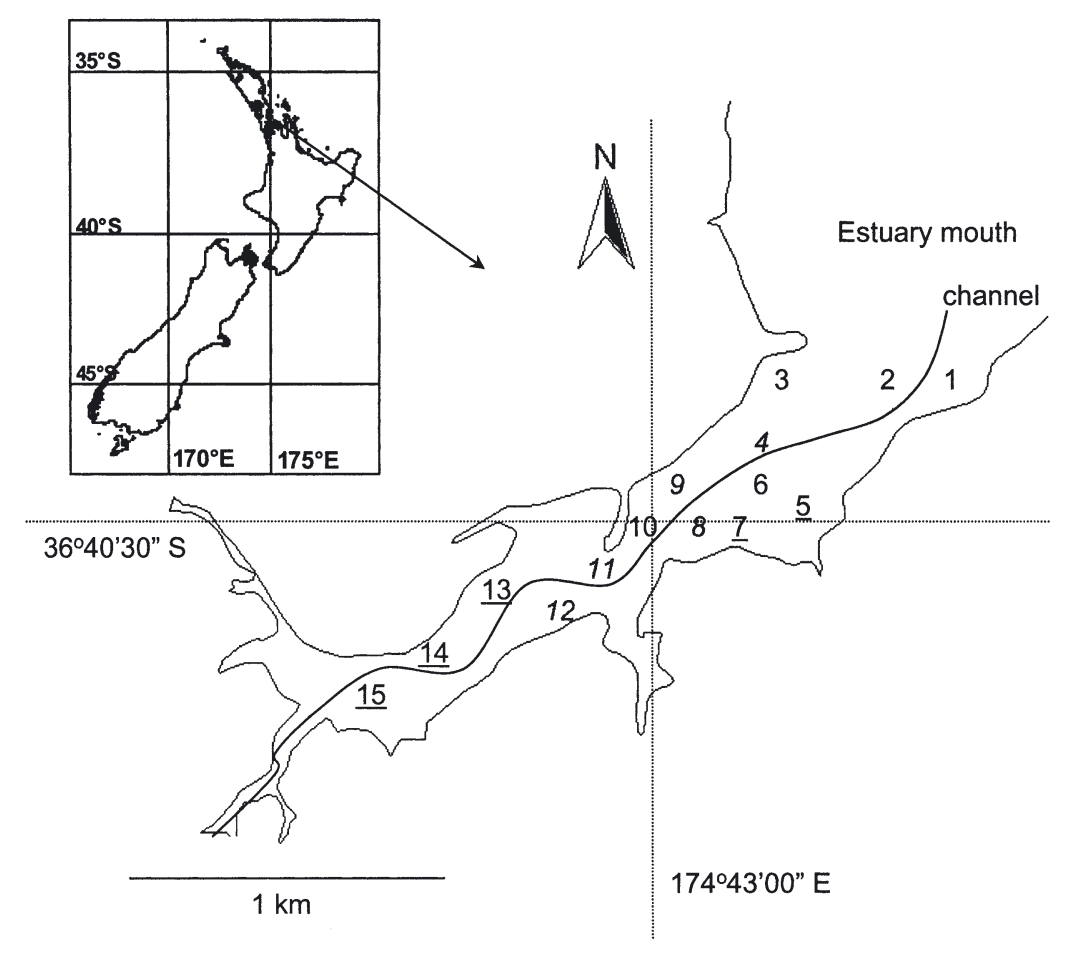

Fig. 1. Map of sampling sites in Okura estuary. Site numbers in normal type, in italics and underlined = low-, medium- and high-deposition areas, respectively (after Fig. 3 of Cooper et al. 1999). Spatial extent of each site $=50 \mathrm{~m}$ along channel and $25 \mathrm{~m}$ perpendicular to channel. Sites numbered sequentially from outer to inner reaches of the estuary 
Measures of sedimentation. Sedimentation was characterised at each site by a combination of a sediment trap and a depth-of-disturbance rod. A sediment trap ( $3.6 \mathrm{~cm}$ diameter $\times 50 \mathrm{~cm}$ deep) was dug into the sediments at the lowest point of each site so that the opening was 20 to $25 \mathrm{~cm}$ above the sediment surface. These traps collected sediment settling from the water column. The height of sediment traps differed by a maximum of $89 \mathrm{~cm}$, and preliminary examination of data from 4 times of collection showed no significant relationship between the height of traps and the amount of sediment collected. Heights of barnacles on nearby poles indicated that each trap was submerged regularly by 1 to $1.5 \mathrm{~m}$ of tide.

Depth-of-disturbance rods (Clifton 1969) consisted of an iron reinforcing rod driven into the sediment $\sim 1 \mathrm{~m}$ from the sediment trap until exactly $20 \mathrm{~cm}$ protruded from the sediment surface. Measurements were then taken between the top of the rod and the ambient sediment surface at least once a month. The height of the rod above the sediment surface indicates the net erosion or accretion at a site. Recorded as a difference from the height observed at the previous visit to the site, this measure will hereafter be called 'bed-height change'. Change in sediment bed height can be closely related to bed-load movement (Grant et al. 1997) and has been used by many studies to characterise sediment dynamics (Pickrill 1979, Carling 1982, Grant et al. 1997).

Sediment traps were deployed at each site in the field for a period of $1 \mathrm{wk}$ in each month from August 2001 to April 2002. At deployment and collection of the sediment traps, measurements of the depth-ofdisturbance rods were also taken. We collected 6 to 8 sediment traps (a few were lost), and made 14 measurements of bed height at each site over the 9 mo study period. Bed-height change and the amount of trapped sediment were both standardised by the number of days since the previous measurement and were therefore recorded in units of $\mathrm{cm} \mathrm{d}^{-1}$ and $\mathrm{g} \mathrm{cm}^{-2} \mathrm{~d}^{-1}$, respectively. Sediment never accumulated to a depth of $35 \mathrm{~cm}$ within any tube. This ensured that the aspect ratio of the sediment traps was greater than $5: 1$; therefore resuspension in conditions of linear flow would not occur (White 1990).

Sediment collected from traps was filtered (mesh size $\sim 2 \mu \mathrm{m})$, dried and weighed. The subsequent analysis was conducted on samples from 3 occasions when all sediment traps were recovered: 12 October 2001, 19 April 2002 and 15 May 2002. These sediments were deflocculated $(0.2 \%$ Calgon for $24 \mathrm{~h})$ and then wet-sieved through 2000, 125 and $63 \mu \mathrm{m}$ sieves. The fractions retained on the sieves were then dried and weighed to obtain the percentage weight of the grain-size fractions 125 to $2000 \mu \mathrm{m}, 63$ to $125 \mu \mathrm{m}$ and $<63 \mu \mathrm{m}$ diameter. The environmental variables measured and subsequently included in analyses are given in Table 1.

Statistical analyses. All analyses were completed at the level of individual sites, with abundances of macrofauna summed across the cores per site $(n=6)$. The relationship between the multivariate species data and the environmental variables (described in Table 1) was analysed using nonparametric multivariate multiple

Table 1. Environmental variables (and abbreviations) used in multivariate models

\begin{tabular}{|c|c|c|}
\hline \multirow{2}{*}{ Group } & \multicolumn{2}{|c|}{ Variable } \\
\hline & Abbreviation & Description \\
\hline Deposition (HML) & $\begin{array}{l}\text { HvML } \\
\text { MvL }\end{array}$ & $\begin{array}{l}\text { Contrast between high and medium/low sites } \\
\text { Contrast between medium and low sites }\end{array}$ \\
\hline Grain size (GS) & $\begin{array}{l}\text { GS1 - GS5 } \\
\text { GS1 } \\
\text { GS2 } \\
\text { GS3 } \\
\text { GS4 } \\
\text { GS5 }\end{array}$ & $\begin{array}{l}5 \text { variables expressing percentage of grain-sizes of ambient } \\
\text { sediments (by weight) falling into particular grain-size classes: } \\
<65.5 \mu \mathrm{m} \\
65.5-120.7 \mu \mathrm{m} \\
120.7-258.9 \mu \mathrm{m} \\
258.9-555.7 \mu \mathrm{m} \\
>555.7 \mu \mathrm{m}\end{array}$ \\
\hline Trapped & $\begin{array}{l}\text { Sdep } \\
\text { Perfin } \\
\text { gt125 }\end{array}$ & $\begin{array}{l}\text { Average total sediment deposition obtained in traps }\left(\mathrm{g} \mathrm{cm}^{-2} \mathrm{~d}^{-1}\right) \\
\% \text { of sediment in traps }<63 \mu \mathrm{m} \text { (percentage of fines) } \\
\% \text { of sediment in traps }>125 \mu \mathrm{m}\end{array}$ \\
\hline Bed-height change & $\begin{array}{c}\mathrm{BH} \\
\mathrm{sdBH}\end{array}$ & $\begin{array}{l}\text { Average change in bed height (erosion/accretion) }\left(\mathrm{cm} \mathrm{d}^{-1}\right) \\
\mathrm{SD} \text { of change in bed height }\left(\mathrm{cm} \mathrm{d}^{-1}\right)\end{array}$ \\
\hline Distance & $\begin{array}{l}\mathrm{D} \\
\mathrm{D} 2\end{array}$ & $\begin{array}{l}\text { Rank distance of site from mouth of estuary }(1-15) \\
\text { Rank distance squared }\left(D^{2}\right)\end{array}$ \\
\hline Organics & Org & Sediment organic matter $(\%)$ \\
\hline Chlorophyll a & Chl a & Chl a ( $\mu \mathrm{g} \mathrm{g}^{-1}$ of wet wt) \\
\hline
\end{tabular}


regression (McArdle \& Anderson 2001). Individual variables were analysed separately for their relationship with the multivariate species data (ignoring other variables), and variables were then subjected to a stepwise forward-selection procedure to develop a model of the species data. Analyses were also completed on sets of environmental variables that formed natural groups (Table 1). All tests were based on Bray-Curtis dissimilarities, calculated among observations for transformed macrofaunal data $\left(y^{\prime}=\ln [y+1]\right)$. p-values for the marginal tests (examining a single variable or group of variables) were obtained using 4999 permutations of the raw data, while conditional tests (used for the forward-selection procedure) were done using 4999 permutations of residuals under the reduced model (Anderson 2001). All non-parametric multivariate multiple regressions were done using the computer program DISTLM (Anderson 2002).

To visualise patterns in multivariate data, we used unconstrained and constrained ordination methods. First, an unconstrained non-metric multi-dimensional scaling (MDS) plot was done, based on Bray-Curtis dissimilarities of $y^{\prime}=\ln (y+1)$-transformed assemblage data. A projection biplot was drawn onto these MDS axes to examine their relationship with (1) environmental variables and (2) abundances of taxa. Next, a constrained ordination, a distance-based redundancy analysis (dbRDA, Legendre \& Anderson 1999), was done, to explicitly investigate the relationship between environmental variables (all those listed in Table 1 except HvML and MvL) and the community assemblage. Principal coordinate (PCO) axes, based on a Bray-Curtis dissimilarity matrix (calculated from the transformed species data), and using Correction Method 1 to correct for negative eigenvalues (see Legendre \& Anderson 1999 for details), were obtained using the program DistPCoA (Legendre \& Anderson 1998). The RDA of the environmental variables, with projections, was then done on the complete set of these PCO axes using the MultivEcol package (freely available from Brian McArdle's website: http://www.stat. auckland.ac.nz/people.php) with the R statistical program (Ihaka \& Gentleman 1996). This package was also used to draw all of the unconstrained MDS plots.

Taxa that were numerically abundant and/or clearly visible in either the unconstrained or constrained biplots were then analysed individually using generalised linear models (GLMs, e.g. McCullagh \& Nelder 1989). As the data consisted of counts, we used, in each case, a GLM with Poisson error and a log link. The linear model is fit on the log scale, so resulting models are multiplicative on the scale of the original variables. The Poisson distribution assumes equal mean and variance, whereas for species abundance data, the variance very often exceeds the mean considerably. Thus, we used the quasi-likelihood approach to model this overdispersion (e.g. McCullagh \& Nelder 1989). Tests involving differences in deviances from models were corrected for overdispersion using a dispersion parameter. This was estimated by the generalised Pearson statistic (the sum of squared residuals divided by fitted values) divided by the residual degrees of freedom (see p. 328 in McCullagh \& Nelder 1989). Nevertheless, variables with an overdispersion parameter greater than 10 should be viewed with serious caution as to the adequacy of the model. Predictor variables for each model were selected from all environmental variables using backwards elimination of non-significant terms ( $p>0.1$ to exclude). All predictor variables were first normalised to $z$-scores (divided by the standard deviation of that variable) to allow direct comparison of parameter coefficients in the fitted models. The computer program $\mathrm{R}$ was used for all GLMs (Ihaka \& Gentleman 1996).

Analysis of variance (ANOVA) was used to test for significant differences among sites and depositional environments for each of the 4 size fractions of trapped sediment $(\%<63 \mu \mathrm{m}, 63-125 \mu \mathrm{m}, 125-250 \mu \mathrm{m}$ and 250-500 $\mu \mathrm{m})$, and for the total amount of sediment trapped. To achieve a balanced design, 6 replicate measures were used from each site. Percentage data were arcsine square-root-transformed prior to analysis (i.e. $\left.y^{\prime}=\sin -1(\sqrt{ } y)\right)$.

\section{RESULTS}

\section{Measures of sedimentation}

Proportions of ambient grain-sizes of sediments differed significantly from site to site and in different depositional environments (Table 2). High-deposition

Table 2. Results of 2-factor nested analyses of variance examining effects of predicted areas of differential probability of sediment deposition: high, medium or low as modelled by Green \& Oldman (1999) and of sites nested within deposition environments on each of 4 different grain-size fractions of ambient sediments. Data were transformed to arcsine squareroots before analysis. Assumption of homogeneity of variance was satisfied only for the 63-125 and 250-500 $\mu \mathrm{m}$ fractions (Cochran's $C$-test, $\mathrm{p}>0.05$ ); therefore, results for other variables should be viewed with caution. Here and in Tables 3 \& 4 , p-values in boldface indicate statistically significant effects (at significance level of $\alpha=0.05$ ), unless stated otherwise

\begin{tabular}{|lrcrc|}
\hline \multirow{2}{*}{$\begin{array}{l}\text { Grain-size fraction } \\
(\mu \mathrm{m})\end{array}$} & \multicolumn{2}{c}{ Sites } & \multicolumn{2}{c|}{ Deposition } \\
& $F_{2,12}$ & $\mathrm{p}$ & $F_{12,75}$ & $\mathrm{p}$ \\
\hline$<63$ & 9.28 & $<\mathbf{0 . 0 0 1}$ & 16.01 & $<\mathbf{0 . 0 0 1}$ \\
$63-125$ & 15.98 & $<\mathbf{0 . 0 0 1}$ & 9.28 & $\mathbf{0 . 0 0 4}$ \\
$125-250$ & 18.16 & $<\mathbf{0 . 0 0 1}$ & 9.55 & $\mathbf{0 . 0 0 3}$ \\
$250-500$ & 7.25 & $<\mathbf{0 . 0 0 1}$ & 7.98 & $\mathbf{0 . 0 0 6}$ \\
\hline
\end{tabular}




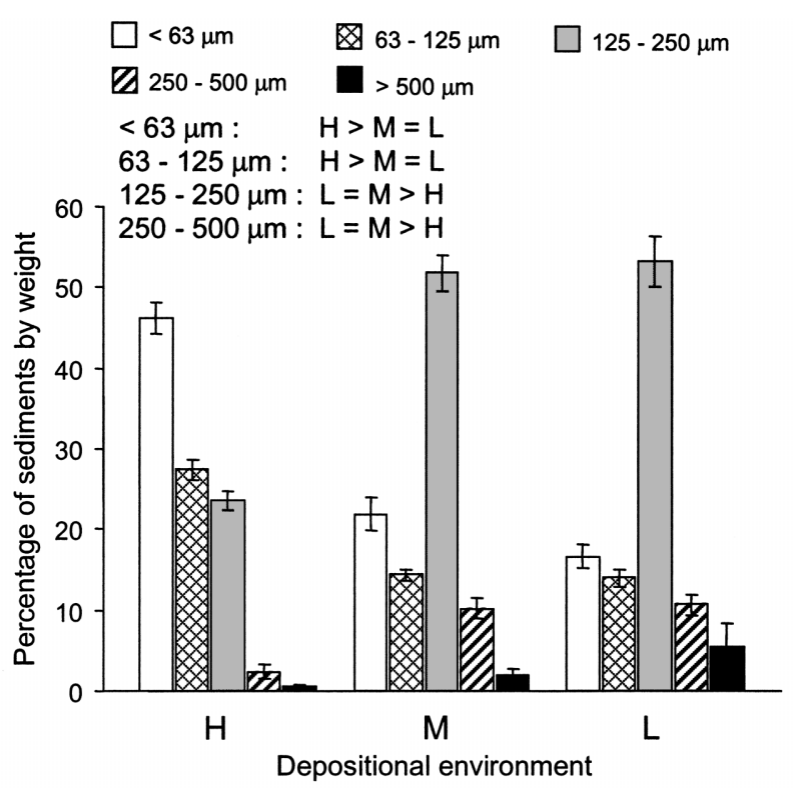

Fig. 2. Average $( \pm 1 \mathrm{SE})$ percentage of sediments of different grain sizes for different depositional classifications $(\mathrm{n}=30$ ). Results of a posteriori pairwise comparisons using StudentNewman-Keuls (SNK) tests are also shown. Inequalities indicate significant difference $(\alpha=0.05)_{i}=$ indicates no significant difference between groups (i.e. $\mathrm{p}>0.05)$. H, M, L: high-, medium-, low-deposition areas, respectively

areas showed, on average, significantly greater percentages of fine ( 0 to $125 \mu \mathrm{m}$ diameter) and significantly smaller percentages of coarse (125 to $500 \mu \mathrm{m}$ diameter) sediments than either medium- or lowdepositional areas (Fig. 2). Although there was significant site-to-site variability in the total amount of trapped sediments $\left(F_{12,101}=9.14, \mathrm{p}<0.0001\right)$, there were no significant differences among the 3 deposition areas in the total amount of sediment accumulated in traps $\left(F_{2,12}=0.86, \mathrm{p}>0.44\right.$, Fig. 3a). One site (Site $8, \mathrm{a}$ medium-deposition site) had a consistently greater average accumulation of sediments than any other site, and the total sediment deposited here was also much more variable than at other sites (Fig. 3a). Profiles of proportions of grain sizes in trapped sediments were not significantly different in the 3 different a priori depositional environments (Fig. 3b) $\left(F_{2,12}=1.37, \mathrm{p}=\right.$ 0.29 for $<63 \mu \mathrm{m}, F_{2,12}=0.46, \mathrm{p}=0.64$ for 63 to $125 \mu \mathrm{m}$, and $F_{2,12}=1.40, \mathrm{p}<0.28$ for $\left.>125 \mu \mathrm{m}\right)$. Thus, the 3 different deposition types $(\mathrm{H}, \mathrm{M}$ and $\mathrm{L})$ modelled by Green \& Oldman (1999) did not differ significantly in the total amount of sediment deposited (Fig. 3a), or in terms of the composition of sediments being deposited (Fig. 3b), but did differ in terms of the composition of the ambient sediments they contained (Fig. 2). In addition, the grain-size profiles for ambient sediments were very different from those for trapped sediments at the medium- and low-deposition sites (cf. Figs. 2 \& 3). This suggests ongoing resuspension at medium- and lowdeposition sites, as higher proportions of fine sediments are deposited at these sites than are retained in the ambient bed.

\section{Multivariate analyses}

A total of 73 taxa from 6 phyla were obtained in this study. A complete list of the taxa is given in Appendix 1. Although there were 6 sampling occasions for each of 15 sites, producing a total of 90 observations, 2 of the observations did not contain data for the variable organics, and were therefore omitted from analysis. Thus, 88 observations were included in the models of the 73 taxa.
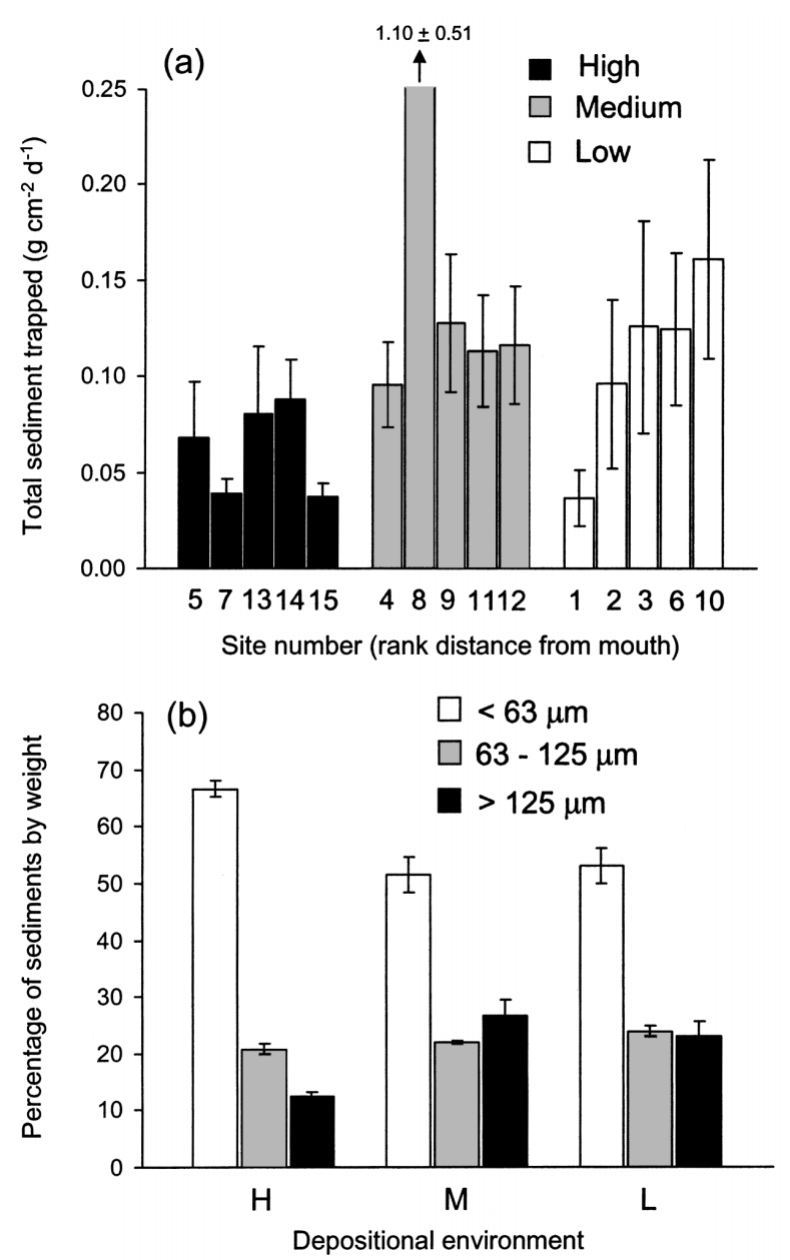

Fig. 3. Average $( \pm 1 \mathrm{SE})$ (a) total weight of sediments in traps from sites in different depositional environments (calculated on $\mathrm{n}=6$ to 8 occasions at each site), and (b) percentages of sediments of different grain sizes collected in traps in different depositional environments (calculated from data for 5 sites) 
Table 3. Results of non-parametric multiple regression of multivariate species data on individual environmental variables for (a) each variable taken individually (ignoring other variables) and (b) forward-selection of variables, where amount explained by each variable added to model is conditional on variables already in the model (i.e. those variables listed above it). \%Var: percentage of variance in species data explained by that variable; Cum. \%: cumulative percentage of variance explained. Variable abbreviations as in Table 1

\begin{tabular}{|c|c|c|c|c|}
\hline Variable & $\% \operatorname{Var}$ & $F$ & $\mathrm{p}$ & Cum. (\%) \\
\hline \multicolumn{5}{|c|}{ (a) Variables individually } \\
\hline HvML & $31.77 \%$ & 40.038 & 0.0002 & \\
\hline GS1 & $26.17 \%$ & 30.487 & 0.0002 & \\
\hline GS2 & $24.98 \%$ & 28.636 & 0.0002 & \\
\hline GS4 & $22.75 \%$ & 25.324 & 0.0002 & \\
\hline GS3 & $22.13 \%$ & 24.434 & 0.0002 & \\
\hline D2 & $16.58 \%$ & 17.097 & 0.0002 & \\
\hline $\mathrm{D}$ & $15.82 \%$ & 16.163 & 0.0002 & \\
\hline Perfin & $13.90 \%$ & 13.886 & 0.0002 & \\
\hline Sdep & $12.40 \%$ & 12.175 & 0.0002 & \\
\hline gt125 & $11.67 \%$ & 11.367 & 0.0002 & \\
\hline Org & $9.12 \%$ & 8.633 & 0.0002 & \\
\hline $\mathrm{sdBH}$ & $7.05 \%$ & 6.521 & 0.0002 & \\
\hline GS5 & $5.91 \%$ & 5.405 & 0.0006 & \\
\hline MvL & $4.08 \%$ & 3.660 & 0.0040 & \\
\hline $\mathrm{BH}$ & $3.93 \%$ & 3.515 & 0.0054 & \\
\hline Chl a & $2.00 \%$ & 1.753 & 0.1052 & \\
\hline \multicolumn{5}{|c|}{ (b) Variables fitted sequentially } \\
\hline HvML & $31.77 \%$ & 40.038 & 0.0002 & 31.77 \\
\hline GS4 & $7.44 \%$ & 10.406 & 0.0002 & 39.21 \\
\hline GS3 & $5.89 \%$ & 9.019 & 0.0002 & 45.10 \\
\hline $\mathrm{BH}$ & $4.22 \%$ & 6.911 & 0.0002 & 49.32 \\
\hline Sdep & $3.65 \%$ & 6.365 & 0.0002 & 52.97 \\
\hline D2 & $2.56 \%$ & 4.670 & 0.0002 & 55.54 \\
\hline $\mathrm{D}$ & $2.16 \%$ & 4.090 & 0.0002 & 57.70 \\
\hline GS2 & $2.02 \%$ & 3.956 & 0.0002 & 59.72 \\
\hline MvL & $2.23 \%$ & 4.562 & 0.0002 & 61.94 \\
\hline gt125 & $2.25 \%$ & 4.840 & 0.0002 & 64.19 \\
\hline Perfin & $2.61 \%$ & 5.973 & 0.0002 & 66.80 \\
\hline GS1 & $1.48 \%$ & 3.511 & 0.0004 & 68.29 \\
\hline Org & $0.97 \%$ & 2.331 & 0.0080 & 69.25 \\
\hline $\mathrm{sdBH}$ & $0.77 \%$ & 1.886 & 0.0420 & 70.03 \\
\hline Chl a & $0.73 \%$ & 1.786 & 0.0560 & 70.75 \\
\hline
\end{tabular}

Nonparametric multivariate regression (McArdle \& Anderson 2001) showed that 15 environmental variables (i.e. all variables in Table 1 except GS5, which is redundant after fitting GS1 to GS4, since these variables sum to $100 \%$ ) together explained $70.75 \%$ of the variance in the species data, which was highly significant (pseudo $F_{15,72}=11.63, \mathrm{p}=0.0002$ ). The variable that explained the greatest amount of variation was the contrast between high- and medium-/low-deposition sites (i.e. HvML, 31.8\%), followed closely by ambient grain-size variables (i.e. GS1 to GS4 each independently explained over $20 \%$; Table 3a). Chlorophyll a (chl a) was the only variable that did not have a significant relationship with the species data when considered singly ( $p=0.1052$; Table 3a).
When building a model, the extent to which the variables overlap in their explanation of the assemblage data must be considered. That is, the environmental variables are themselves correlated. Thus, a sequential model was built using forward-selection (Table 3b). Note how the percentage of variation explained by (for example) the proportions of ambient grain sizes (GS1 to GS4) was dramatically reduced after taking into account the contrast of high- versus medium- and lowdeposition sites (i.e. GS4 explained only $7.4 \%$ after removing effects due to HvML; Table 3b). Nevertheless, the sequential model shows that most of the variables added significantly to our ability to explain variation in the species data, as evidenced by the $p$-values in the table of forward-selection results (Table $3 \mathrm{~b}$ ). Only chl a appeared to be unnecessary for the combined model ( $\mathrm{p}>0.05$, Table $3 \mathrm{~b}$ ).

The results of the multivariate analyses of whole sets of variables are shown in Table 4 . The set of variables with the greatest explanatory power was the set of ambient grain-size variables, which explained $41.8 \%$ of the variation in the species data. It is interesting to

Table 4. Results of non-parametric multiple regression of multivariate species data on sets of environmental variables for (a) each set of variables taken individually (ignoring other sets) and (b) forward-selection of sets of variables, where amounts explained by each set added to the model is conditional on sets of variables already in the model (i.e. those sets of variables listed above it). \%Var: percentage of variance in species data explained by that set of variables and Cum. \%: cumulative percentage of variance explained. Individual variables in each set are shown in Table 1 . Note that the set of 'erosion' variables explained a greater percentage of the variation in the species data than the 'trapped' variables in the forward-selection procedure; this is not an error, but can be caused by sets of variables together explaining greater variability in the response data than the sum of the variation explained by either set alone. See p. 533 in Legendre \& Legendre (1998) for further details

\begin{tabular}{|lcrcc|}
\hline Set & \%Var & $F$ & $\mathrm{p}$ & Cum. (\%) \\
\hline \multicolumn{2}{l}{ (a) Sets individually } & & & \\
GS & 41.82 & 14.915 & $\mathbf{0 . 0 0 0 2}$ & \\
HML & 35.85 & 23.750 & $\mathbf{0 . 0 0 0 2}$ & \\
Trapped & 20.25 & 7.110 & $\mathbf{0 . 0 0 0 2}$ & \\
Distance & 19.74 & 10.454 & $\mathbf{0 . 0 0 0 2}$ & \\
Erosion & 11.92 & 5.754 & $\mathbf{0 . 0 0 0 2}$ & \\
Org & 9.12 & 8.633 & $\mathbf{0 . 0 0 0 2}$ & \\
Chl a & 2.00 & 1.753 & 0.1052 & \\
(b) Sets fitted sequentially & & & \\
GS & 41.82 & 14.915 & $\mathbf{0 . 0 0 0 2}$ & 41.82 \\
HML & 10.93 & 9.371 & $\mathbf{0 . 0 0 0 2}$ & 52.75 \\
Trapped & 6.38 & 4.058 & $\mathbf{0 . 0 0 0 2}$ & 59.13 \\
Erosion & 6.52 & 7.219 & $\mathbf{0 . 0 0 0 2}$ & 65.66 \\
Distance & 3.37 & 4.030 & $\mathbf{0 . 0 0 0 2}$ & 69.03 \\
Org & 1.00 & 2.437 & $\mathbf{0 . 0 0 9 0}$ & 70.03 \\
Chl $a$ & 0.73 & 1.786 & 0.0566 & 70.75 \\
\multicolumn{5}{l}{} \\
\hline
\end{tabular}




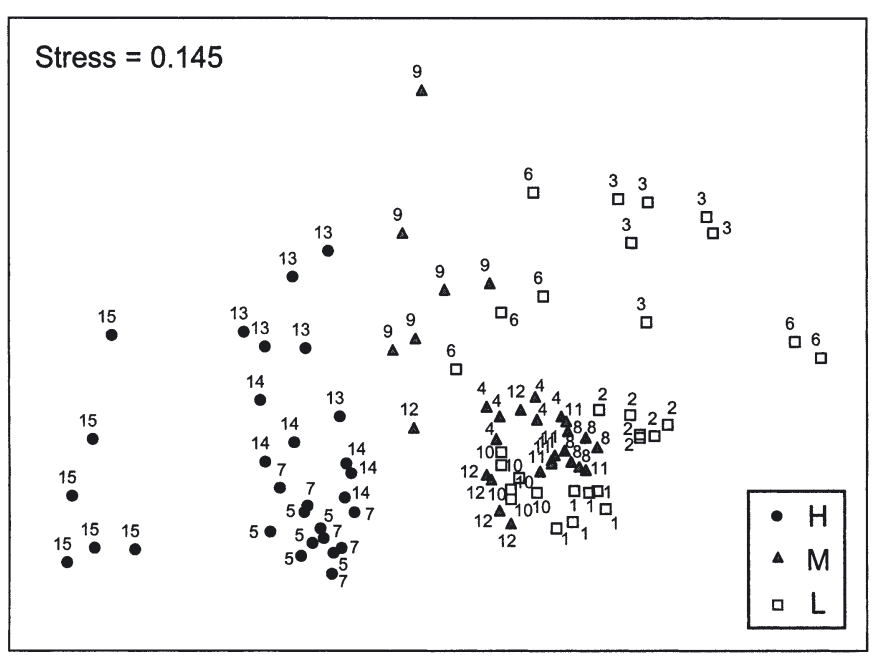

Fig. 4. Non-metric MDS ordination of the 73 taxa showing deposition categories $(\mathrm{H}$ : high; $\mathrm{M}$ : medium; L: low) of sites numbered (as in Fig. 1). Analysis performed on Bray-Curtis dissimilarities of $\ln (y+1)$-transformed data

note that the information obtained from trapped sediments alone explained over $20 \%$ of the variation in the species data (Table 4a). Once the ambient grain-size variables were fitted, the next most important set was the a priori modelled depositional environments (i.e. HML), followed by information from trapped sediments (i.e. short-term sediment-deposition information). These explained an additional 10.9 and $6.4 \%$ of the variation in the species data, respectively (Table 4b). Bed-height change variables added about another $6 \%$ to the explained variation (Table $4 \mathrm{~b}$ ). Distance variables and organics, while only adding another 3 and $1 \%$ to the explained variation, respectively, were, nevertheless, statistically significant. Only chl a appeared, once again, to be redundant in the model ( $p>0.05$, Table $4 \mathrm{~b}$ ).

The MDS ordination showed that assemblages at individual sites taken at 6 different times through the year tended to cluster together (Fig. 4). Note, however, that the sites were not clearly ordered from the mouth to the upper reaches of the estuary, indicating that distances among assemblages were not strongly correlated with distances on the map (cf. Figs. 1 \& 4). Also, a clear separation between high- and medium- or lowdeposition environments was evident in the MDS plot (Fig. 4). Although there was not a clean separation between the assemblages from medium- and those from low-deposition environments, there did appear to be a gradient in the plot from high (on the left) to low (on the right) (Fig. 4). The environmental factors most strongly correlated with the MDS axes were the ambient grainsize variables (GS1 to GS4), with greater proportions of the small ambient grain sizes (GS1 and GS2) being associated with assemblages in 'high'-deposition environments, and greater proportions of coarse ambient grain sizes (GS3 and GS4) being associated with assemblages in low (or medium)-deposition environments (Fig. 5). Areas of 'high'-deposition probability were also those areas which tended to be further from the mouth of the estuary (i.e. see positions of Arrows D and D2 in Fig. 5), to have greater proportions of fine sediments in traps (Perfin) and to have sediments with greater organic content (Org) (Fig. 5). On the other hand, the assemblages of low- and medium-deposition areas tended to have greater proportions of coarse sediments in traps and, rather curiously perhaps, a greater total amount of sediment deposited (see position of Sdep arrow in Fig. 5 and cf. Fig. 3a data). Bed-height change variables (BH and $\mathrm{sdBH}$ ) and chl a did not show strong relationships with the MDS axes (Fig. 5).

The organisms most strongly associated with medium- or low-deposition environments were the bivalves Austrovenus stutchburyi (Austr), Nucula hartvigiana (Nucul), Paphies australis (Paphi), other molluscs such as the chiton Sypharochiton pelliserpentis (Sypha), and the gastropods Cominella glandiformis (Comgl) and Notoacmea helmsii (Notoa) (Fig. 6). Also

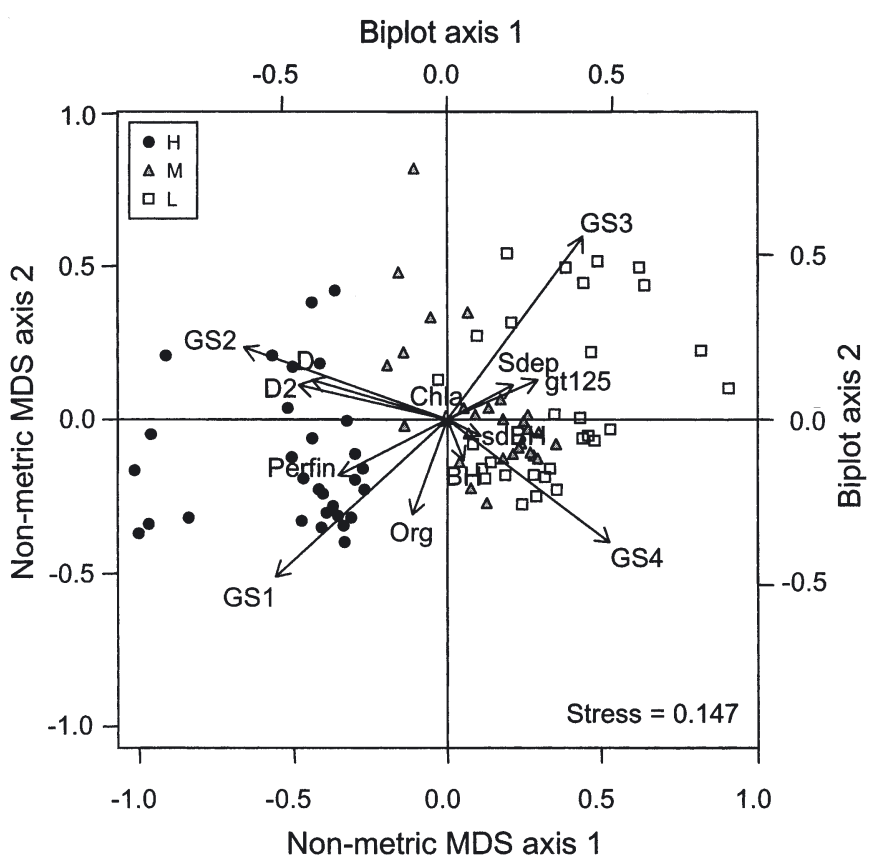

Fig. 5. Projection biplot of the environmental variables in Table 1 onto non-metric MDS ordination of 73 taxa based on Bray-Curtis dissimilarities of $\ln (y+1)$-transformed data. This ordination has a slightly different stress value from that in Fig. 4, since 2 of the 90 observations were omitted here because of the missing value for environmental variable 'organics'. Variable abbreviations as in Table 1 
more abundant in these environments, not surprisingly, were organisms that live on the shells of cockles (A. stutchburyi), such as the barnacle Elminius modestus (Elmin) and the anemone Anthopleura sp. (Antho) (Fig. 6). Assemblages in low-/medium-deposition environments were also characterised by the presence or greater abundance of some crustaceans, including the amphipods Waitangi sp. (Waita), Paracalliope sp. (Parak) and Phoxocephalid sp. (Phoxo), the cumacean Colorustylis lemurum (Color) and the decapod Halicarcinus sp. (Halic). In addition, greater abundances of several polychaete worms were found in these environments, including Prionospio (Prion), Macroclymenella stewartensis (Macro), Aonides sp. (Aonid) and other syllids (OthSy) (Fig. 6).

In contrast, 'high'-deposition environments were characterised primarily by larger relative abundances of several polychaete worms, including nereids, Cossura coasta (Cossu), Notomastus sp. (Notom), Glycera lamellipoda (Glyla) and other glycerids (OthGl), Boccardia spp. (Bocca), Scoloplos cylindifer (Scolo) and other orbinids (OthOr), oligochaetes (Oligo), Polydora spp. (Polyd) and pectinarids (Pecti) (Fig. 6). In addition, there were greater numbers of Helice sp. and Macrophthalmus sp. crabs in these 'high'-deposition environments (Helic, Fig. 6).

The constrained ordination plot showed patterns similar to those in the unconstrained MDS plot (cf. Figs. 5 \& 7). The first 2 dbRDA axes explained $22.4 \%$ of

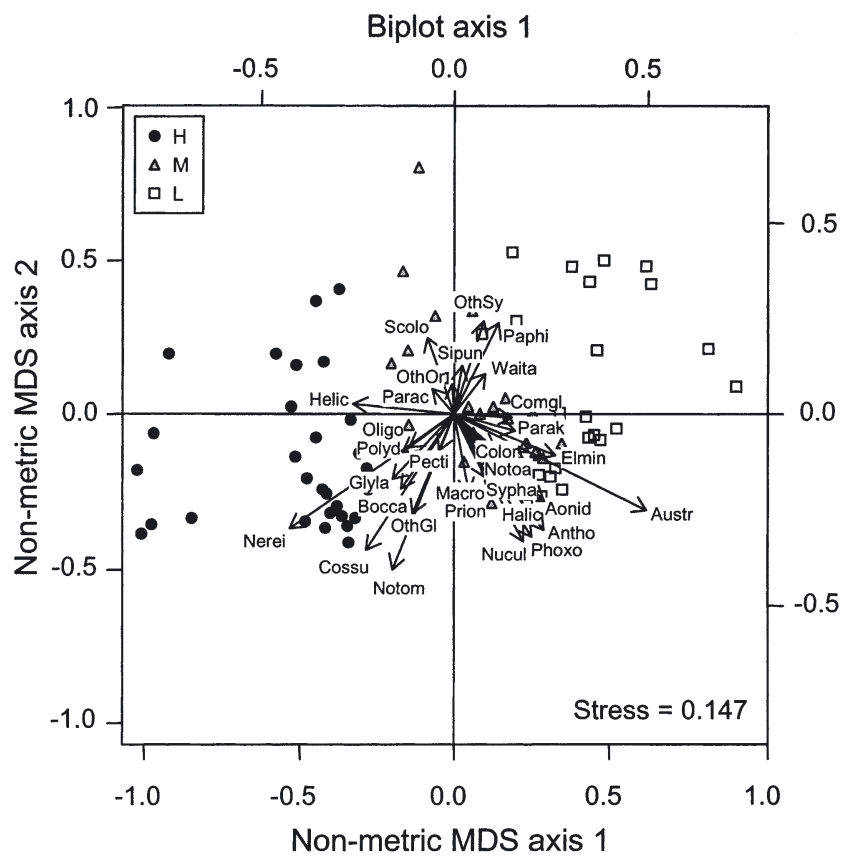

Fig. 6. Projection biplot of individual taxa onto non-metric MDS ordination of all 73 taxa based on Bray-Curtis dissimilarities of $\ln (y+1)$-transformed data. Taxa abbreviations as in Appendix 1

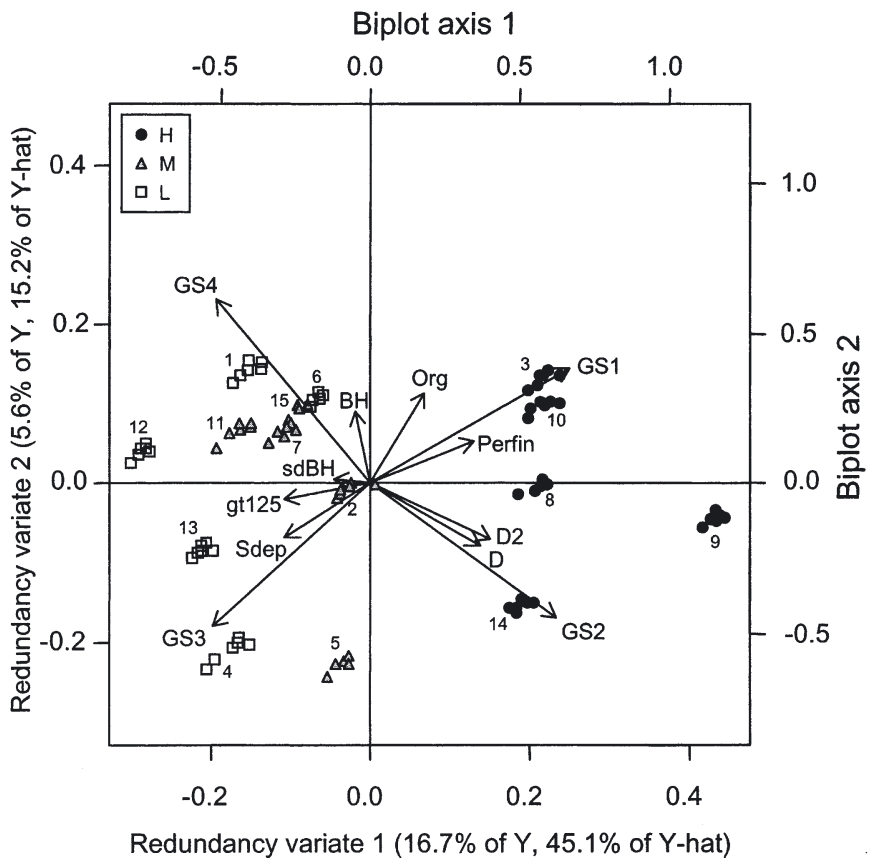

Fig. 7. Distance-based RDA ordination relating environmental variables to faunal data, showing biplot projections for environmental variables in Table 1 and clusters of data points at various sites (numbered as in Fig. 1). Analysis was performed on principal coordinate axes obtained from BrayCurtis dissimilarities of $\ln (y+1)$-transformed species counts, with Correction Method 1 for negative eigenvalues (see Legendre \& Anderson 1999). '\% of $y^{\prime}$ indicates the percentage of the variability in the original data explained by the axis and $' \%$ of $y$-hat' indicates the percentage of the variation in the fitted matrix (i.e. the fitted relationship between y and the explanatory variables) explained by the axis. Note that for dbROA the ' $y$ ' matrix in the RDA actually consists of principal coordinate axes from the (corrected) distance matrix

the variability in the species data and $60.3 \%$ of the relationship between the species and the environmental variables (Fig. 7). There was a clear separation between the 'high'-deposition sites (on the right-hand side) and the medium- and low-deposition sites (on the left-hand side) (Fig. 7). This occurred even though the variables identifying these depositional categories (HvML and MvL) were not included as explanatory variables in the dbRDA analysis. The fact that these patterns are shown in both the constrained and unconstrained plots indicates that (1) differences in assemblages are well identified by the model developed by Green \& Oldman (1999) (based on hydrodynamics), and (2) the types of differences in assemblages promoted by the depositional model of Green \& Oldman (1999) are also well-modelled by the environmental variables we included in our study. It also suggests that these environmental variables are those driving the greatest differences among assemblages in the Okura system (i.e. they describe the directions of greatest 


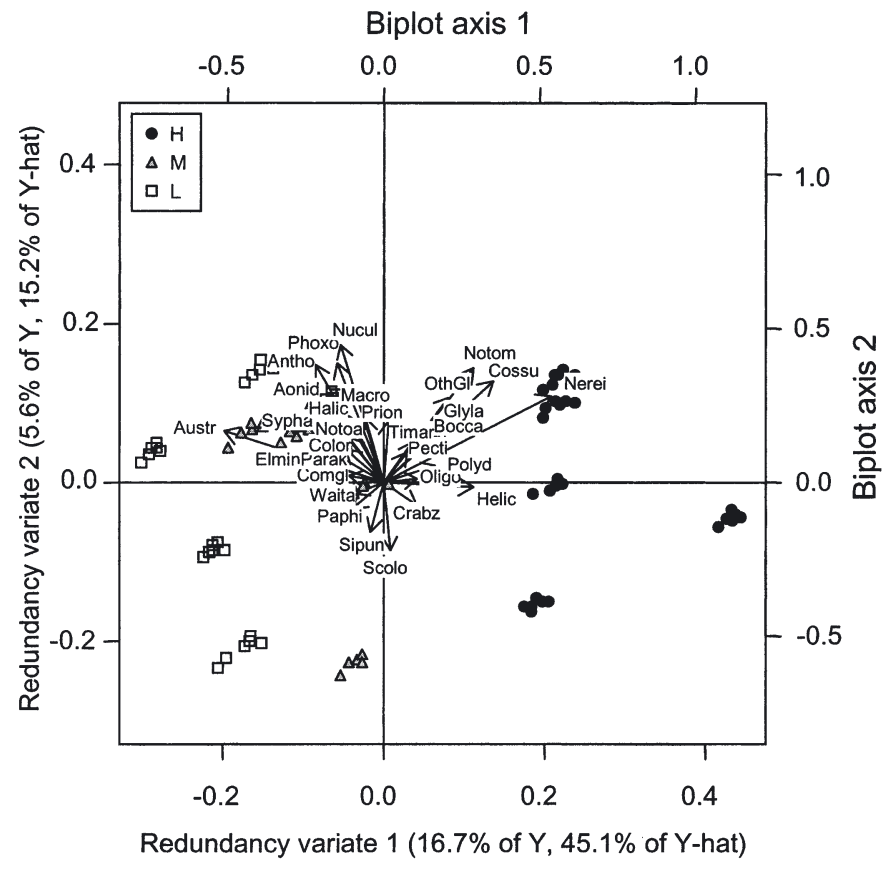

Fig 8. Distance-based RDA as in Fig. 7, but here with projections of individual taxa onto the ordination axes. Taxa abbreviated as in Appendix 1

variation in multivariate space, e.g. Anderson \& Willis 2003)

The positions of the arrows relative to the sites in the dbRDA biplot for environmental variables (Fig. 7) were very similar to those in the unconstrained biplot (Fig. 5), with the possible exception of the bed height change variables. In the dbRDA biplot, variation in bed-height had a visibly positive association with the second redundancy variate, which it did not have in the unconstrained plot. This suggests that effects of bedheight change on the assemblages may be occurring in a direction perpendicular to the strong effects of depositional environments, ambient sediment characteristics and sedimentation (trapped sediments).

Observations through time for the sites are so close together in the dbRDA plot, that each of the 15 individ-

Table 5. Estimates of parameters from generalised linear models of abundant taxa with environmental variables using log-link and Poisson errors. Abundances from 6 cores per site were pooled for analysis. Int = intercept, \%Dev = model deviance/total deviance, and Odisp = the Pearson overdispersion parameter; other abbreviations used here for environmental variables are given in Table 1. Taxa are listed in order of decreasing deviance \%. Spaces indicate no significant relationship beween taxon and environmental variables

\begin{tabular}{|c|c|c|c|c|c|c|c|c|}
\hline & \multirow[b]{2}{*}{ Int } & \multicolumn{4}{|c|}{ Ambient sediments } & \multicolumn{3}{|c|}{ Trapped sediments } \\
\hline & & Gs1 & Gs2 & Gs3 & Gs4 & Sdep & Perfin & gt125 \\
\hline Cossura coasta & -6.2 & 2.4 & & & & -0.3 & & 1.1 \\
\hline Aonides spp. & -60.5 & 6.5 & 8.0 & 9.0 & 8.6 & & 1.1 & -4.1 \\
\hline Anthopleura spp. & -23.7 & 0.8 & 4.6 & 3.4 & 6.2 & & 0.04 & -1.2 \\
\hline Austrovenus stutchburyi & -10.5 & 1.4 & 2.3 & 2.7 & 2.8 & -0.9 & 0.02 & -0.9 \\
\hline Paphies australis & 41.2 & -4.4 & -6.3 & -4.5 & -4.7 & 2.1 & & -5.0 \\
\hline Nucula hartvigiana & -8.8 & 11.3 & 1.6 & 1.9 & 3.0 & -0.9 & 0.03 & -1.7 \\
\hline Notoacmea helmsii & -30.0 & 1.8 & 3.7 & 3.6 & 4.7 & 1.2 & 0.6 & -0.8 \\
\hline Exogoninae & -34.3 & 6.1 & 6.1 & 4.8 & & 0.19 & -2.7 & -4.4 \\
\hline Scoloplos cylindifer & -122.8 & 15.3 & 16.1 & 19.8 & 14.2 & -4.5 & 0.15 & -2.0 \\
\hline Elminius modestus & -74.3 & 7.1 & 10.8 & 11.8 & 10.5 & -1.7 & & -1.8 \\
\hline Nereid/nicon complex & -23.1 & 3.8 & 2.2 & 3.1 & 2.2 & & 0.03 & -0.2 \\
\hline Notomastus sp. & -0.664 & 1.0 & 0.8 & & -0.4 & 0.04 & -0.7 & -0.8 \\
\hline Sypharochiton pelliserpentis & -15.0 & & & 4.0 & 3.5 & & & \\
\hline Phoxocephalid & 1.3 & 0.5 & -1.5 & 1.1 & 0.8 & -0.4 & & 0.3 \\
\hline Prionospio sp. & -22.7 & 3.2 & 3.1 & 3.7 & 3.8 & & 0.04 & -0.6 \\
\hline Pectinariidae & 2.4 & 1.0 & 1.2 & & & 0.08 & -1.0 & \\
\hline Waitangi sp. & 19.5 & & -11.0 & -5.9 & & 0.14 & & 0.9 \\
\hline Parakalliope sp. & 0.5 & & -1.2 & & 2.1 & 1.8 & -4.6 & 3.7 \\
\hline Macomona liliana & 0.9 & & 0.4 & 0.9 & & -0.6 & 1.3 & -0.9 \\
\hline Other glycerids & 1.6 & & -0.6 & & 0.7 & -0.03 & & 0.4 \\
\hline Halicarcinus sp. & -12.0 & 1.3 & 1.9 & 2.2 & & 0.06 & -1.0 & \\
\hline Helice/macropthalmus & -7.0 & 1.3 & 0.8 & 1.5 & & -0.6 & 0.04 & -0.6 \\
\hline Colorustylis lemurum & -1.3 & & 0.6 & 1.1 & & & & \\
\hline Boccardia spp. & 6.9 & & -2.8 & -1.2 & 1.6 & 1.3 & 0.09 & \\
\hline Oligochaetes & 150.3 & -20.0 & -12.0 & -24.0 & -12.6 & -3.8 & -4.6 & 17.9 \\
\hline Glycera lamellipoda & -0.3 & 0.3 & & & 0.02 & -0.3 & & 0.2 \\
\hline Orbinia papillosa & -15.6 & 1.6 & 1.7 & 2.1 & 2.1 & & & \\
\hline Psuedopolydora sp. & 6.3 & & -0.8 & -0.8 & -0.9 & & & \\
\hline Psuedosphaeroma sp. & 0.7 & & -1.2 & & 0.7 & 0.03 & & \\
\hline Nemerteans & 4.5 & -0.5 & -0.5 & -0.8 & & 0.6 & & \\
\hline
\end{tabular}


ual sites appears as a cluster of 6 points on the diagram and can be identified by site number (Fig. 7). The temporal clustering in the dbRDA (Fig. 7) accentuated the clustering in the MDS (Fig. 5). This is simply due to the fact that the majority of the explanatory variables in the analysis (excluding organics and chl a) were the same at each time of sampling. Thus, when the assemblage data are viewed through the filter of the dbRDA (a constrained ordination) the similarity in environmental values at each site at each time minimised the relatively small temporal variance in the MDS biplot (Fig. 5).

The projection of species axes onto the dbRDA is very similar to that in the MDS biplot (cf. Figs. 6 \& 8). The dbRDA plot does, however, reveal a positive association between abundances of the polychaete Timarete anchylochaeta (Timar) and crab zoea (Crabz) with 'high'-deposition environments (Fig. 8) which was not evident in the unconstrained biplot.

The statistical analyses (Tables 3 \& 4) and ordinations (Figs. 5 \& 7 ) all indicated that ambient grain-sizes of sediments, the classification of sites in terms of depositional probability (after Green \& Oldman 1999) and information about trapped sediments (i.e. shortterm sedimentation) are all important in terms of explaining the variability in macrofaunal communities.

\section{Univariate analyses}

The results of GLMs for individual taxa are summarised in Table 5. The percentage of the deviance explained by the GLM model for the taxa we investigated here ranged from 93 to $20 \%$. Most of the taxa produced models that were interpretable by reference to the results presented graphically in the biplots, but finer biological details were also potentially interpretable. For example, the cockle Austrovenus stutchburyi showed a strong positive relationship with the proportions of medium-to-coarse ambient grain sizes of sediments (GS2 to GS4), but it also showed a slight positive relationship with the percentage of fine sediments deposited at a site (Perfin) and a negative relationship with the total amount of sediment deposited (Sdep). A similar model was obtained for the barnacle Elminius modestus and the anemones Anthopleura spp. In general, the percentage of fine sediments in traps (Perfin) did appear to have a small but positive net effect on most taxa, including the polychaetes Waitangi sp. and Boccardia spp. Exogonids showed the strongest positive effect of these fine-deposit sediments, and they were also affected positively by changes in bed height at a site (Table 5). In fact, oligochaetes, Sypharochiton pelliserpentis, Scoloplos

\begin{tabular}{|c|c|c|c|c|c|c|c|c|c|}
\hline \multicolumn{2}{|c|}{ Distance } & \multicolumn{2}{|c|}{ Bed height } & \multirow[b]{2}{*}{ Chl a } & \multirow[b]{2}{*}{ Org } & \multicolumn{2}{|c|}{ Deposition } & \multirow[b]{2}{*}{$\%$ Dev } & \multirow[b]{2}{*}{ Odisp } \\
\hline $\mathrm{D}$ & D2 & $\mathrm{Bh}$ & Sdbh & & & Hvml & $\mathrm{Mvl}$ & & \\
\hline & & 0.1 & -2.2 & & 93 & 3.1 & & & \\
\hline 2.1 & -0.5 & 0.3 & & & -0.8 & 93 & 6.4 & & \\
\hline-1.2 & & 0.6 & 0.5 & & & 1.1 & -0.5 & 91 & 3.6 \\
\hline-0.2 & & 0.2 & 0.8 & 0.03 & & 0.3 & 91 & 6.6 & \\
\hline 4.9 & & -1.1 & & & 1.7 & 90 & 11.6 & & \\
\hline \multirow[t]{2}{*}{1.7} & -1.1 & & 1.0 & & & 0.4 & -0.9 & 83 & 8.7 \\
\hline & 0.4 & & 0.06 & & -1.0 & 81 & 4.7 & & \\
\hline 5.2 & 1.5 & 1.6 & -0.16 & -0.8 & & & 80 & 3.2 & \\
\hline \multirow[t]{2}{*}{-6.4} & 4.5 & -1.0 & 2.7 & & 0.4 & & & 80 & 4.4 \\
\hline & 0.4 & 1.1 & & 0.1 & & -1.6 & 79 & 13.8 & \\
\hline-1.8 & 1.9 & & 0.3 & & & & 77 & 1.2 & \\
\hline 1.6 & & 0.4 & 0.07 & & -0.5 & -0.2 & 73 & 19.7 & \\
\hline 1.3 & & -0.2 & 0.5 & -1.4 & 71 & 1.0 & & & \\
\hline 0.7 & & 0.2 & -0.6 & -0.5 & 69 & 5.6 & & & \\
\hline-1.3 & 1.2 & & 0.4 & & -0.2 & & -0.7 & 68 & 25.7 \\
\hline \multirow[t]{4}{*}{0.9} & & & 0.5 & & & 68 & 4.8 & & \\
\hline & & 1.0 & -2.3 & 2.9 & 66 & 2.6 & & & \\
\hline & -1.8 & -0.42 & & & 62 & 9.3 & & & \\
\hline & 0.2 & & & 0.3 & -0.5 & 58 & 2.5 & & \\
\hline \multirow[t]{4}{*}{0.4} & & 0.08 & 0.2 & & -0.9 & 58 & 2.4 & & \\
\hline & 0.4 & 0.8 & & 0.2 & & & 54 & 1.2 & \\
\hline & & 0.4 & & 0.3 & & & 51 & 4.5 & \\
\hline & & & & 47 & 15.5 & & & & \\
\hline-2.9 & 3.2 & & -0.9 & & & 0.7 & 45 & 3.3 & \\
\hline \multirow{4}{*}{-13.7} & 2.9 & & & & 0.8 & 41 & 6.6 & & \\
\hline & & 0.2 & & & 32 & 2.8 & & & \\
\hline & & & 0.4 & & & 26 & 2.5 & & \\
\hline & & & & & 22 & 16.2 & & & \\
\hline \multirow[t]{2}{*}{0.4} & & 0.2 & & & 21 & 2.0 & & & \\
\hline & & 0.2 & -0.3 & 0.07 & 0.1 & 0.3 & & 20 & 4.2 \\
\hline
\end{tabular}


cylindifer and exogonids were apparently the most strongly affected (of any of the taxa measured here) by variation in bed height $(\mathrm{BH})$ at sites, a result which cannot be seen clearly in the ordination diagrams. The bivalves Paphies australis and Austrovenus stutchburyi also had negative associations with increasing distance from the mouth of the estuary, while the opposite was true for the other 2 bivalves, Macomona liliana and Nucula hartvigiana. The limpet Notoacmea helmsii, the bivalve Paphies australis and the chiton Sypharochiton pelliserpentis were molluscs that, perhaps surprisingly, all showed positive relationships with the total amount of sediment deposited.

One of the simplest models was also the most powerful at predicting abundance. This was the model obtained for the polychaete worm Cossura coasta, which had a strong positive association with fine ambient grain sizes of sediments (GS1), a negative association with coarse deposited sediments (gt125), a positive association with high- versus medium- or low-deposition areas (HvML) and a positive association with organics (Org). These 4 variables plus the squared distance from the mouth of the estuary accounted for $93 \%$ of the total deviance for this species. This relative utility yet simplicity was rivalled by the model for the cumacean Colorustylis lemurum, for which only 2 variables (GS3 and GS4) accounted for $47 \%$ of the total deviance.

\section{DISCUSSION}

Of the variation in macrofaunal assemblages in the Okura estuary, $70 \%$ was explained using 15 environmental variables. This suggests an extremely strong link between sediment characteristics and the infauna of the Okura estuary. Of the variation in macrofaunal assemblages in the Okura estuary, $42 \%$ was explained by variation in the grain-size fractions of ambient sediments. Ambient sediment characteristics have long been recognised as important in structuring benthic communities (Thorson 1957, Gray 1974, Flach 1993).

The fact that measurements of ambient grain-size characteristics were only measured on 1 occasion during the study and yet still explained such a large proportion of the macrofaunal variation is interesting. Changes in ambient sediments can occur through geological time (e.g. estuarine infilling, which potentially takes centuries) and little change is generally seen over the scale of a single year (Gouleau et al. 2000, Widdows et al. 2000). Sudden short-term changes as a result of deposition of large amounts of usually waterborne sediments can, however, also occur (Schubel 1974). Although we found no evidence of sudden changes during the course of this study (as measured by sediment traps and depth-of-disturbance rods), ongoing monitoring of Okura estuary will include repeated measures of the ambient sediment structure, which is potentially variable.

The total average amount and characteristics of trapped sediments (i.e. measurable sedimentation) were also important in explaining macrofaunal assemblage variation. The idea that sediment deposition, regardless of its food content, may influence the composition of communities is relatively recent (Edgar \& Barrett 2000, Norkko et al. 2002, Airoldi 2003). There has, however, been much research into closely related fields, i.e. of the impact of seston concentrations upon filter feeders (e.g. the review of Jorgensen 1996, Ellis et al. 2002) and the influence of organic matter on soft-sediment assemblages (e.g. Pearson \& Rosenberg 1978).

The total amount of trapped sediment (i.e. sediment input) had a negative effect on the bivalve Austrovenus stutchburyi, while the percentage of fine sediment in these traps had a small positive influence on the density of this species (Table 5). This species is a filter feeder (Grange 1977, Pridmore et al. 1991, Williams \& Pilditch 1997) that may respond positively to small additions of fine sediment that can be used as a food source; however, when large total deposits of sediment occur, this could inhibit feeding and result in smothering or death (e.g. Norkko et al. 2002). Such effects have been seen for many filter-feeding bivalves (see the review by Jorgensen 1996). For example, both the feeding success and distribution of Atrina zelandica are affected by sedimentation (Ellis et al. 2002). Nucula hartvigiana is a deposit-feeding bivalve (Grange 1977) that showed the same pattern of response as A. stutchburyi, however it is unclear whether its response was due to a similar mechanism. Elminius modestus (a barnacle) and Anthopleura spp. (an anemone) are both filter feeders that live upon Austrovenus stutchburyi shells. Anthopleura spp. showed similar relationships with the textural components of trapped sediments to those seen for A. stutchburyi. E. modestus showed a negative relationship with the total average amount of sediment trapped (Sdep), as did A. stutchburyi, although Anthopleura spp. did not. This may indicate that Anthopleura spp. is more tolerant of sediment deposition than either its host or its competitor for space on A. stutchburyi shells. Clearly, much more specific manipulative studies of individual taxa are required to obtain a greater knowledge of the mechanisms underlying the patterns revealed by the models used in the present study.

Some previous models have explained between 10 and $90 \%$ of the variation in abundance of taxa in softsediment communities using physical and biological predictor variables (Legendre et al. 1997, Ysebaert \& 
Herman 2002, Ysebaert et al. 2002). This large range in explained variance from different modelling studies is probably due to differences among studies in the scale of observation relative to physical gradients. For example, physical processes may be relatively unimportant compared to smaller-scale biological processes on a relatively homogeneous sand-flat covering a large area. Legendre et al. (1997) found that predictor variables explained 10 to $70 \%$ of the variation in species data over a physically relatively homogeneous sandflat. In contrast, studies examining variation along 1 or more strong physical ecological gradients, such as those along an entire estuary, may have greater modelling success (e.g. Ysebaert \& Herman 2002, Ysebaert et al. 2002 and this study, which, in each case, explained 70 to $90 \%$ of the variation in the species data). In a comparable study to our own in the Scheldt estuary, high proportions of variance in species data were explained by several environmental variables, including salinity, mud content, chl a and bed-level height (Ysebaert \& Herman 2002). Our work reinforces the findings of previous studies, suggesting that environmental forces strongly influence the spatial structuring of estuarine macrobenthic communities. In addition, we suggest that information concerning the amount and nature of sediment deposited at individual sites within an estuary (as measured by sediment traps) can be useful in modelling these communities and populations over the scale of whole estuaries. Furthermore, such information is not redundant to information concerning ambient sediments at particular sites: ambient sediments and trapped sediments can have quite different characteristics and can elicit different kinds of responses in organisms at particular sites. Information about both trapped and ambient sediments, along with information concerning bedheight change, can contribute positively towards the development of useful models.

This study made no attempt to separate recently derived terrestrial sediments from resuspended sediment caught in traps. This might be achieved through careful experimental tracer studies. Such studies would be necessary in order to attribute any specific effects of sedimentation to terrestrial origins or causes for the purpose of coastal management.

Measuring the influx of sediment to a site is difficult. Bed-load traps will not allow separation of sedimentation caused by new sediment input as opposed to small-scale movements of existing ambient sediments, while turbidity meters will not necessarily measure sediment settling. We used water-column traps, but these may suffer from resuspension in the presence of waves, particularly at more exposed sites (Grant et al. 1997). Nevertheless, high-, medium- and lowdeposition sites were interspersed throughout the estu- ary, which ensured that they could not be systematically affected by different exposures. This also meant that trapped sediments in different depositional environments would not have experienced systematic differences in the probability of resuspension. In a previous study in another estuary in the Auckland region (the Manukau), resuspension from water-column traps was only observed at times of high wind speed, which probably generated wave action at the site (Grant et al. 1997). Thus, resuspension is likely to be most important in the more exposed outer reaches of the Okura estuary (Green \& MacDonald 2001). However, we found that the greatest grain-size fraction for trapped sediments in all parts of the estuary was that of the fine sediments, which are the most likely to be resuspended; this also indicated that resuspension was probably not of great importance in determining the contents of sediments in traps. Fine sediments are also the most likely to be of terrestrial origin, given the finegrained nature of local clay soils, and hence of greatest interest to this study.

Another possible weakness of our methodology was that we attempted to relate sedimentation at a single point to biology across the whole site $(50 \times 25 \mathrm{~m})$. However, the scale of the differences in the average amount of trapped sediments among sites (greater than 1 order of magnitude) indicated that small-scale variation in sedimentation within sites or in trapping efficiencies were not likely to obscure larger-scale patterns. In addition, other studies in the Auckland region have shown that spatial variation in trapped sediments from the water column (15 $\mathrm{cm}$ above the bed) across homogeneous sites had low coefficients of variation (10 to $30 \%$, Commito et al. 1995, Grant et al. 1997). Overall, the advantage of our measure of sedimentation was that it measured quantity and texture of sediments, it was integrated over time, and it could be used easily and efficiently over the relevant spatial and temporal scales of interest.

The depositional classes of Green \& Oldman (1999) showed a strong relationship with relative grain-size proportions of ambient sediments (Fig. 2). 'High'deposition sites were characterised by relatively greater amounts of fine ambient sediments, while low-deposition areas had smaller proportions of fine ambient sediments. Nevertheless, the grain-size fractions for trapped sediments at the sites did not differ significantly among the 3 depositional environments (Fig. 3b). In addition, the total amount of sediments deposited was, in general, no greater in the so-called high-depositional areas than in the medium- or lowdepositional environments identified by Green \& Oldman (1999). There may be several reasons for this. First, our sediment traps did not account for resuspension, therefore low-deposition sites may have similar 
rates of deposition, but much higher rates of resuspension from the bed, which was not measured. Second, resuspension is not expected to be equal for different grain-size fractions, with finer sediments generally being more likely to be resuspended. Third, sediment deposition can be temporally very patchy. The majority of sediment deposition arises from heavy rainfall (Dyer 1986, Hicks \& Griffiths 1992) events, and perhaps rainfall events during the present study were not heavy enough to cause depositions large enough to characterise the different depositional environments within the estuary. However, because of the strong relationships between (1) ambient sediments and depositional classification and (2) depositional classification and infaunal community structure, Green \& Oldman's (1999) depositional model was generally well supported by our results.

Although attributing causes and sources for particular effects of sedimentation can be difficult, this study delivers an important message: natural communities respond to natural changes in the levels of sedimentation occurring in an estuary. It is only by reference to these known effects in the unperturbed system that any consequences of potential unnatural changes in sedimentation can be understood and managed.

Acknowledgements. Our thanks to the many workers who helped on this project: S. Burgess, S. Crofts, D. Egli, E. Franke, O. Haine, L. Kozmian-Ledward, V. Lorenzi, M. Lienart, G. Nesbitt and J. Saunders. The Leigh Laboratory discussion group and 2 anonymous reviewers helped to improve this paper, and we thank them for their input. This project was supported by funds from the Auckland Regional Council and the University of Auckland.

\section{LITERATURE CITED}

Airoldi L (2003) The effects of sedimentation on rocky coast assemblages. Oceanogr Mar Biol Annu Rev 41:161-236

Airoldi L, Cinelli F (1997) Effects of sedimentation on subtidal macroalgal assemblages: an experimental study from a Mediterranean rocky shore. J Exp Mar Biol Ecol 215: 269-288

Anderson MJ (2001) Permutation tests for univariate or multivariate analysis of variance and regression. Can J Fish Aquat Sci 58:626-639

Anderson MJ (2002) DISTLM v.2: a FORTRAN computer program to calculate a distance-based multivariate analysis for a linear model. Department of Statistics, University of Auckland

Anderson MJ, Willis TJ (2003) Canonical analysis of principal coordinates: a useful method of constrained ordination for ecology. Ecology 84:511-525

Armonies W, Hellwig-Armonies M (1992) Passive settlement of Macoma balthica spat on tidal flats of the Dutch Wadden Sea and subsequent migration of juveniles. Neth J Sea Res 29:371-378

Byers J (2000) Competition between two estuarine snails: implications for invasions of exotic species. Ecology 81: 1225-1239
Carling P (1982) Temporal and spatial variation in intertidal sedimentation rates. Sedimentology 29:17-23

Chou LM (1996) Response of Singapore reefs to land reclamation. Galaxea 13:85-92

Clifton HE (1969) Beach lamination: nature and origin. Mar Geol 7:553-559

Commito JA, Thrush SF, Pridmore RD, Hewitt JE, Cummings VJ (1995) Dispersal dynamics in a wind-driven benthic system. Limnol Oceanogr 40:1513-1518

Constable AJ (1999) Ecology of benthic macro-invertebrates in soft-sediment environments: a review of progress towards quantitative models and predictions. Aust J Ecol $24: 452-476$

Cooper AB, Green MO, Norkko A, Oldman JW, Stroud MJ, Thrush SF (1999) Assessment of sediment impacts on Okura estuary associated with catchment development: synthesis. Report No ARC90241/2. National Institute of Water and Atmospheric Research, Hamilton, New Zealand

Dyer KR (1986) Coastal and estuarine sediment dynamics, Chichester. Wiley-Interscience, New York

Edgar G, Barrett N (2000) Effects of catchment activities on macrofaunal assemblages in Tasmanian estuaries. Estuar Coast Shelf Sci 50:639-654

Ellis DV (1988) Case histories of coastal and marine mines. In: Salomons W, Forstner U (eds) Chemistry and biology of solid waste: dredged material and mine tailing. SpringerVerlag, Berlin, p 73-100

Ellis J, Cummings V, Hewitt J, Thrush S, Norkko A (2002) Determining effects of suspended sediment on condition of a suspension feeding bivalve (Atrina zelandica): results of a survey, a laboratory experiment and a field transplant experiment. J Exp Mar Biol Ecol 267:147-174

Flach EC (1993) The distribution of the amphipod Corophium arenarium in the Dutch Wadden Sea - relationships with sediment composition and the presence of cockles and lugworms. Neth J Sea Res 31:281-290

GESAMP (Joint Group of Experts on the Scientific Aspects of Marine Pollution) (1990) The state of the environment. Blackwell Scientific Publications, Oxford

Gouleau D, Jouanneau JM, Weber O, Sauriau PG (2000) Shortand long-term sedimentation on Montportail-Brouage intertidal mudflat, Marennes-Oleron Bay (France). Contin Shelf Res 20:1513-1530

Grange KR (1977) Littoral benthos-sediment relationships in Manukau Harbour, New Zealand. N Z J Mar Freshw Res 11:111-123

Grant J, Turner SJ, Legendre P, Hume TM, Bell RG (1997) Patterns of sediment reworking and transport over small spatial scales on an intertidal sandflat, Manukau Harbour, New Zealand. J Exp Mar Biol Ecol 216:33-50

Gray JS (1974) Animal-sediment relationships. Oceanogr Mar Biol Annu Rev 12:223-261

Green MO, MacDonald IT (2001) Processes driving estuary infilling by marine sands on an embayed coast. Mar Geol 178:11-37

Green MO, Oldman JW (1999) Deposition of flood-borne sediment in Okura estuary. Report No. ARC90242/2. National Institute of Water and Amospheric Research, Hamilton, New Zealand

Hentschel BT, Jumars PA (1994) In situ chemical inhibition of benthic diatom growth affects recruitment of competing, permanent and temporary meiofauna. Limnol Oceanogr 39:816-838

Hicks DM, Griffiths G (1992) Sediment load. In: Mosley M (ed) Waters of New Zealand. Caxton Press, Christchurch, p 229-248 
Ihaka R, Gentleman R (1996) R: a language for data analysis and graphics. J Comput Graph Stat 5:299-314

Jorgensen C (1996) Bivalve filter feeding revisited. Mar Ecol Prog Ser 142:287-302

Kennish JK (1995) Ecology of estuaries: Anthropogenic effects. CRC Press, Boca Raton

Legendre P, Anderson MJ (1998) Program DistPCoA. Département de Sciences Biologiques, Université de Montréal, Québec

Legendre P, Anderson MJ (1999) Distance-based redundancy analysis: testing multispecies responses in multifactorial ecological experiments. Ecol Monogr 69:1-24

Legendre P, Legendre L (1998) Numerical ecology, 2nd English edn. Elsevier Science, Amsterdam

Legendre P, Thrush SF, Cummings VJ, Dayton PK and 9 others (1997) Spatial structure of bivalves in a sandflat: scale and generating processes. J Exp Mar Biol Ecol 216:99-128

McArdle BH, Anderson MJ (2001) Fitting multivariate models to community data: a comment on distance-based redundancy analysis. Ecology 82:290-297

McCullagh P, Nelder JA (1989) Generalised linear models, 2nd edn. Chapman \& Hall, London

Norkko A, Thrush SF, Hewitt JE, Norkko JT, Cummings VJ, Ellis JI, Funnell GA, Schultz D (1999) Ecological effects of sediment deposition in Okura estuary. Report No ARC90243. National Institute of Water and Atmospheric Research, Hamilton, New Zealand

Norkko A, Thrush SF, Hewitt JE, Cummings VJ and 5 others (2002) Smothering of estuarine sandflats by terrigenous clay: the role of wind-wave disturbance and bioturbation in site-dependent macrofaunal recovery. Mar Ecol Prog Ser 234:23-41

Oliver JS, Slattery PN (1985) Destruction and opportunity on the seafloor: effects of gray whale feeding. Ecology 66: 1965-1975

Pearson TH, Rosenberg R (1978) Macrobenthic succession in relation to organic enrichment and pollution in the marine environment. Oceanogr Mar Biol Annu Rev 16: $229-311$

Peters RH (1991) A critique for ecology. Cambridge University Press, Cambridge

Peterson CH (1985) Patterns of lagoonal bivalve mortality after heavy sedimentation and their paleoecological significance. Paleobiology 11:139-153

Pickrill RA (1979) A micro-morphological study of intertidal estuarine surfaces in Pauatahanui Inlet, Porirua Harbour. N Z J Mar Freshw Res 13:59-69

Porra RJ, Thompson WA, Kreidmann PE (1989) Determination of accurate extinction coefficients and simultaneous equations for assaying chlorophylls $a$ and $b$ extracted with four different solvents: verification of the concentration of chlorophyll standards by atomic absorption spectroscopy. Biochem Biophys Acta 975:384-394

Pridmore RD, Thrush SF, Wilcock RJ, Smith TJ, Hewitt JE, Cummings VJ (1991) Effect of the organochlorine pesticide technical chlordane on the population structure of suspension and deposit feeding bivalves. Mar Ecol Prog Ser 76:261-271

Probert PK (1984) Disturbance, sediment stability, and trophic structure of soft-bottom communities. J Mar Res 42: 893-921

Quigley MP, Hall JA (1999) Recovery of macrobenthic communities after maintenance dredging in the Blyth Estuary, north-east England. Aquat Conserv: Mar Freshw Ecosyst 9:63-73

Saiz-Salinas JI, Urkiaga-Alberdi J (1999) Faunal responses to turbidity in a man-modified bay (Bilbao, Spain). Mar Environ Res 47:331-347

Schubel J (1974) Effects of tropical storm Agnes on the suspended solids of the Northern Chesapeake Bay. In: Gibbs $\mathrm{R}$ (ed) Suspended solids in the water, Vol 4. Plenum Marine Science, New York, p 113-132

Smith CR, Kukert H (1996) Macrobenthic community structure, secondary production, and rates of bioturbation and sedimentation at the Kane'ohe Bay Lagoon floor. Pac Sci 50:211-229

Thomas F, Renaud F, de Meeus T, Poulin R (1998) Manipulation of host behaviour by parasites: ecosystem engineering in the intertidal zone? Proc R Soc Lond B 265:1091-1096

Thorson G (1957) Bottom communities. In: Hedgpeth JW (ed) Treatise on marine ecology and paleoecology, Vol 1. Ecology. Waverly Press, Baltimore, p 461-534

Thrush SF, Hewitt JE, Cummings VJ, Dayton PK and 6 others (1998) Disturbance of the marine benthic habitat by commercial fishing: impacts at the scale of the fishery. Ecol Appl 8:866-879

Turner SJ, Thrush SF, Pridmore RD, Hewitt JE, Cummings VJ, Maskery M (1995) Are soft-sediment communities stable? An example from a windy harbour. Mar Ecol Prog Ser 120:219-230

Vogt H, Schramm W (1991) Conspicuous decline of Fucus in Kiel Bay (Western Baltic): what are the causes? Mar Ecol Prog Ser 69:189-194

White J (1990) The use of sediment traps in high-energy environments. Mar Geophys Res 12:145-152

Widdows J, Brown S, Brinsley MD, Salkeld PN, Elliott M (2000) Temporal changes in intertidal sediment erodability: influence of biological and climatic factors. Contin Shelf Res 20:1275-1289

Williams BG, Pilditch CA (1997) The entrainment of persistent tidal rhythmicity in a filter-feeding bivalve using cycles of food availability. J Biol Rhythms 12:173-181

Wood PJ, Armitage PD (1997) Biological effects of fine sediment in the lotic environment. Environ Manag 21:203-217

Ysebaert T, Herman PMJ (2002) Spatial and temporal variation in benthic macrofauna and relationships with environmental variables in an estuarine, intertidal softsediment environment. Mar Ecol Prog Ser 244:105-124

Ysebaert T, Meire P, Herman PMJ, Verbeek H (2002) Macrobenthic species response surfaces along estuarine gradients: prediction by logistic regression. Mar Ecol Prog Ser 225:79-95 
Appendix 1. Taxa recorded and enumerated from sediment cores in Okura estuary. Abbreviations used in Figs. 6 \& 8 for relevant taxa are shown in parentheses

\begin{tabular}{|c|c|c|c|}
\hline Taxon & Group & Taxon & Group \\
\hline \multicolumn{2}{|l|}{ Molluscs } & \multicolumn{2}{|l|}{ Polychaetes } \\
\hline Austrovenus stutchburyi (Austr) & Bivalvia & Notomastus sp. (Notom) & Capitellidae \\
\hline Nucula hartvigiana (Nucul) & Bivalvia & Capitella sp. & Capitellidae \\
\hline Paphies australis (Paphi) & Bivalvia & Timarete anchylochaeta (Timar) & Cirratulidae \\
\hline Macomona liliana & Bivalvia & Other cirratulids & Cirratulidae \\
\hline Arthritica bifurcata & Bivalvia & Cossura coasta (Cossu) & Cossuridae \\
\hline Corbula zelandica & Bivalvia & Diopatra sp. & Eunicea \\
\hline Notoacmea helmsii (Notoa) & Gastropoda & Other glycerids (OthGl) & Glyceridae \\
\hline Sypharochiton pelliserpentis (Sypha) & Gastropoda & Glycera lamellipoda (Glyla) & Glyceridae \\
\hline Cominella glandiformis (Comgl) & Gastropoda & Glycera americana & Glyceridae \\
\hline Diloma subrostratum & Gastropoda & Magelona dakini & Magelonidae \\
\hline Cominella maculosa & Gastropoda & Macroclymenella stewartensis (Macro) & Maldanidae \\
\hline Cominella adspersa & Gastropoda & Aglaophamus macroura & Nephtvidae \\
\hline Turbo smaragdus & Gastropoda & Nereid/nicon complex (Nerei) & Nereidae \\
\hline Haminoea zelandiae & Opisthobranchia & Oligochaetes & Oligochaeta \\
\hline \multirow[t]{2}{*}{ Other Opisthobranchs } & Opisthobranchia & Armandia sp. & Opheliidae \\
\hline & & Travisia sp. & Opheliidae \\
\hline \multicolumn{2}{|l|}{ Crustaceans } & Scoloplos cylindifer (Scolo) & Orbiniidae \\
\hline Phoxocephalid (Phoxo) & Amphipoda & Orbinia papillosa & Orbiniidae \\
\hline Parakalliope sp. (Parak) & Amphipoda & Other orbinids (OthOr) & Orbiniidae \\
\hline Waitangi sp. (Waita) & Amphipoda & Owenia fusiformis & Oweniidae \\
\hline Other amphipods & Amphipoda & Aricidea sp. & Paraonidae \\
\hline Elminius modestus (Elmin) & Cirripedia & Pectinarids (Pecti) & Pectinariidae \\
\hline Copepods & Copepoda & Sabellid sp. & Sabellidae \\
\hline Paracorophium sp. (Parac) & Crustacean & Aonides spp. (Aonid) & Spionidae \\
\hline Unidentified crustaceans & Crustacean & Psuedopolydora spp. & Spionidae \\
\hline Colorustylis lemurum (Color) & Cumacea & Boccardia spp. (Bocca) & Spionidae \\
\hline Helice/Macrophthalmus (Helic) & Decapoda & Polydora spp. (Polyd) & Spionidae \\
\hline Halicarcinus sp. (Halic) & Decapoda & Other spionids & Spionidae \\
\hline Crab zoea (Crabz) & Decapoda & Prionospio complex (Prion) & Spionidae \\
\hline Hemigrapsus crenualtus & Decapoda & Exogoninae & Syllidae \\
\hline Pinnotheres sp. & Decapoda & Other syllids (OthSy) & Syllidae \\
\hline Pagurus sp. & Decapoda & & \\
\hline Psuedosphaeroma sp. & Isopoda & \multicolumn{2}{|l|}{ Others } \\
\hline Other isopods & Isopoda & Anthopleura spp. (Antho) & Anthozoa \\
\hline Cirolana sp. & Isopoda & Other Anthozoa & Anthozoa \\
\hline Leptostracan & Leptostracan & Insect larvae & Insecta \\
\hline \multirow[t]{3}{*}{ Ostracods } & Ostracoda & Nemerteans & Nemertea \\
\hline & & Platyhelminth & Platyhelminth \\
\hline & & Sipunculid (Sipun) & Sipuncula \\
\hline
\end{tabular}

Editorial responsibility: John Gray (Contributing Editor), Oslo, Norway
Submitted: May 20, 2003; Accepted: November 10, 2003 Proofs received from author(s): April 23, 2004 